\title{
DESKRIPSI IKAN FAMILI MUGILIDAE DI LIMA MUARA SUNGAI DI SULAWESI UTARA
}

\author{
Deidy Y Katili ${ }^{1)}$ \\ ${ }^{1)}$ Program Studi Biologi FMIPA Universitas Sam Ratulangi, Manado 95115
}

\begin{abstract}
ABSTRAK
Deskripsi beberapa spesies ikan anggota Famili Mugilidae telah dilakukan di lima muara sungai di Sulawesi Utara. Penelitian ini bertujuan untuk mendeskripsikan, membandingkan aspek morfometrik dan meristik serta mengidentifikasi beberapa spesies ikan tersebut. Sampel ikan diambil dengan metode "appliance catch", yaitu "coastal-throw net". Hasil penelitian menunjukkan adanya 138 ikan yang terbagi dalam 6 spesies dan 4 genus. Spesies ikan yang diidentifikasi ialah. Liza parmata, L. vaigensis, L. macrolepis, Mugil cephalus, Valamugil connesius and Oedalechilus labiosus.
\end{abstract}

Kata kunci: deskripsi, muara sungai, Mugilidae, Sulawesi Utara,

\section{DESCRIPTION OF MUGILIDAE FISH IN FIVE RIVER EUSTUARIES OF NORTH SULAWESI}

\begin{abstract}
Some fish of Mugilidae family in five river eustuaries of North Sulawesi were described. The aims of this research were describe, compare morphometric as well as meristic aspects, and identity these fish species. The appliance catch (coastal and throw net) was used in fish semples. The results showed there were 138 fish that were classofoed as 6 species and 4 genus,i.e. Liza parmata, L. vaigensis, L. macrolepis, Mugil cephalus, Valamugil connesius and Oedalechilus labiosus.
\end{abstract}

Keywords : description, river eustuaries, Mugilidae, North Sulawesi

\section{PENDAHULUAN}

Ikan adalah kelompok vertebrata yang salah satu habitatnya adalah sungai dan memiliki jenis paling banyak. Ikan mendominasi kehidupan perairan diseluruh permukaan bumi. Jumlah spesies ikan yang telah berhasil dicatat adalah sekitar 21.000 spesies dan diperkirakan berkembang mencapai 28.000 spesies. Jumlah spesies ikan yang hidup dipermukaan bumi adalah 21.000 spesies sementara jumlah spesies vertebrata yang ada diperkirakan sekitar 43.173 spsies (Nelson, 1984).

Sulawesi memiliki jumlah spesies ikan yang relatif kurang dibandingkan satwa yang lain. Sulawesi memiliki 68 spesies ikan dibandingkan dengan 132 spesies di Jawa dan 394 di Kalimantan, Akan tetapi telah tercatat tingkat keendemikan ikan di Sulawesi tinggi, dimana $76 \%$ dari jumlah spesies, atau sejumlah 52 spesies adalah endemic, dibandingkan hanya $38 \%$ di Kalimantan (Kottelat, 1993).

Sulawesi Utara merupakan salah satu provinsi yang memiliki satuan wilayah sungai yang luas dan banyak yaitu ada 407 sungai. Sungai merupakan salah satu unsur penting dalam kehidupan manusia, yang dimanfaatkan untuk kepentingan sumber air minum, sumber tenaga listrik, irigasi, perikanan darat, transportasi, bahan baku industri, rekreasi dan olahraga air. Berbagai usaha produksi perikanan dapat dijalankan berkat adanya sistem perairan darat. Menurut Odum (1996) Ekosistem air tawar dibedakan menjadi dua yaitu ekosistem air tenang (lentik) misalnya danau dan rawa. Ekosistem air mengalir (lotik) misalnya sungai dan air terjun. Ciri-ciri ekosistem air tawar yaitu kadar garam atau salinitasnya sangat rendah, variasi suhu sangat rendah, penetrasi cahaya matahari kurang dan dipengaruhi oleh iklim serta cuaca. Ekosistem air tawar salah 
satunya adalah sungai yang mempunyai fungsi sebagai tempat hidup organisme seperti hewan-hewan akuatik (Hutabarat, 2000)

Sulawesi Utara yang memiliki satuan wilayah sungai yang cukup luas, khususnya pada Kabupaten Minahasa Selatan mempunyai 3 sungai yang relatif besar yaitu Sungai Poigar, Sungai Maruasey dan Sungai Ranoyapo sedangkan Minahasa Utara memiliki dua sungai yang relatif besar yaitu Sungai Talawaan dan Sungai Likupang. Sungai yang berfungsi sebagai tempat hidup untuk sejumlah komunitas ikan khususnya Famili Mugilidae yang keberadaannya penting untuk dikembangkan, sehingga dibutuhkan informasi mengenai deskripsi ikan bagian muara dari ke lima sungai tersebut. Penelitian bertujuan Mengidentifikasi dan mendeskripsikan jenis ikan Famili Mugilidae pada lima muara sungai yang ada di Sulawesi Utara yaitu pada Minahasa Selatan (Sungai Poigar, Sungai Maruasey dan Sungai Ranoyapo) dan pada Minahasa Utara (Sungai Talawaan dan Sungai Likupang). Membandingkan morfometrik dan meristik ikan Famili Mugulidae pada lima muara sungai yang ada di Sulawesi Utara.

\section{METODOLOGI PENELITIAN}

Penelitian ini dilaksanakan pada bulan Januari sampai Maret 2010 pada lima muara sungai yaitu muara Sungai Poigar, muara Sungai Maruasey, muara Sungai Talawaan, muara Sungai Likupang dan muara Sungai Ranoyapo. Metode yang digunakan adalah metode sampling. Dalam penelitian ikan ditangkap dengan manggunakan 2 alat yaitu alat tangkap jaring lempar dan jaring pantai. Jaring pantai dengan panjang jaring $40 \mathrm{~m}$ serta lebar $3 \mathrm{~m}$. Penangkapan dilakukan pada saat air laut pasang setinggi $3 \mathrm{~m}$ dan surut setinggi $0,5 \mathrm{~m}$. Penangkapan ikan dilakukan pada bagian muara sungai. Jaring lempar dan jaring pantai digunakan dari tengah sungai sampai pinggir sungai dengan bantuan beberapa orang. Penarikan contoh ikan Famili Mugilidae dilakukan sebanyak enam kali pada satu muara sungai yaitu tiga kali pada saat surut dan tiga kali pada saat pasang. Lokasi pengambilan sampel terdiri atas lima muara sungai. Ikan yang diperoleh dimasukkan ke dalam wadah yang berisi hancuran es selanjutnya ikan contoh dibawa ke Laboratorium. Analisis data yaitu indeks proporsi dan standar deviasi.

\section{HASIL DAN PEMBAHASAN}

\section{Spesies Ikan Famili Mugilidae yang ditemukan Pada lima Muara Sungai Sulawesi Utara}

Jumlah ikan Famili Mugilidae selama pengambilan sampel pada lima muara sungai yang ada di Sulawesi Utara yaitu muara Sungai Poigar, muara Sungai Ranoyapo, muara Sungai Maruasey, muara Sungai Talawaan dan muara Sungai Likupang adalah 138 ekor ikan. Berdasarkan hasil identifikasi maka ditemukan ada 6 spesies dari 95 spesies yang berada diseluruh dunia serta 3 genus dari 13 genus yang tersebar diseluruh dunia. Pada masing-masing muara sungai terdapat perbedaan spesies dan individu yang ditemukan (Tabel 1).

Habitat ikan yang ada pada Tabel 1 yaitu perairan pantai, muara sungai dan air tawar. Ikan Famili Mugilidae hidup dengan memakan materi organik yang terdapat di pasir dan lumpur. Penyebarannya Indopasifik, Afrika Selatan, Laut Merah, Timur Afrika, Jepang serta selatan Great Barrier Reef dan New Caledonia (Kottelat et al., 1993). 
Tabel 1. Spesies ikan Famili Mugilidae yang ditemukan pada lima muara sungai

\begin{tabular}{|l|l|l|l|l|l|l|l|}
\hline No & \multirow{2}{*}{} & Lokasi & \multicolumn{6}{|c|}{ Spesies } \\
\cline { 3 - 8 } & & $\begin{array}{l}\text { Valamugil } \\
\text { connesius }\end{array}$ & $\begin{array}{l}\text { Mugil } \\
\text { cephalus }\end{array}$ & $\begin{array}{l}\text { Liza } \\
\text { macrolepis }\end{array}$ & $\begin{array}{l}\text { Liza } \\
\text { parmata }\end{array}$ & $\begin{array}{l}\text { Oedalechilus } \\
\text { labiosus }\end{array}$ & $\begin{array}{l}\text { Liza } \\
\text { vaigensis }\end{array}$ \\
\hline 1. & $\begin{array}{l}\text { Sungai } \\
\text { Maruasey }\end{array}$ & 21 & 7 & 15 & - & - & - \\
\hline 2. & $\begin{array}{l}\text { Muara } \\
\text { Sungai } \\
\text { Poigar }\end{array}$ & 6 & - & - & 8 & - & - \\
\hline 3. & $\begin{array}{l}\text { Sungai } \\
\text { Ranoyapo }\end{array}$ & - & - & - & - & 5 & 11 \\
\hline 4. & $\begin{array}{l}\text { Sungai } \\
\text { Talawaan }\end{array}$ & - & 12 & - & - & - & 7 \\
\hline 5. & $\begin{array}{l}\text { Sungai } \\
\text { Likupang }\end{array}$ & 46 & - & - & - & - & - \\
\hline
\end{tabular}

Deskripsi Valamugil connesius

$\begin{array}{ll}\text { Kingdom } & \text { : Animalia } \\ \text { Phylum } & \text { : Chordata } \\ \text { Sub phylum } & \text { : Vertebrata } \\ \text { Super Class } & \text { : Osteichthyes } \\ \text { Class } & \text { : Actinopterygii } \\ \text { Ordo } & \text { : Perciformes } \\ \text { Famili } & \text { : Mugilidae } \\ \text { Genus } & \text { : Valamugil } \\ \text { Spesies } & \text { : Valamugil connesius }\end{array}$

\section{Morfologi}

Berdasarkan hasil pengamatan Valamugil connesius memiliki bentuk tubuh yang fusiform serta tubuh simetris bilateral, mulut dapat disembulkan dan posisi mulut inferior, bentuk sirip ekor bercagak, gurat sisi lebih dari satu, tidak mempunyai sungut, posisi sirip ventral terhadap sirip pectoral torasik serta bentuk sisik ctenoid.

\section{Morfometrik}

Hasil perhitungan morfometrik pada diperoleh indeks proporsi antara bagianbagian tubuh Valamugil connesius pada tiga tempat yang berbeda terhadap panjang total tubuh setelah dirata-ratakan nilai paling tinggi adalah panjang garpu sedangkan nilai rata-rata yang paling rendah adalah tinggi di

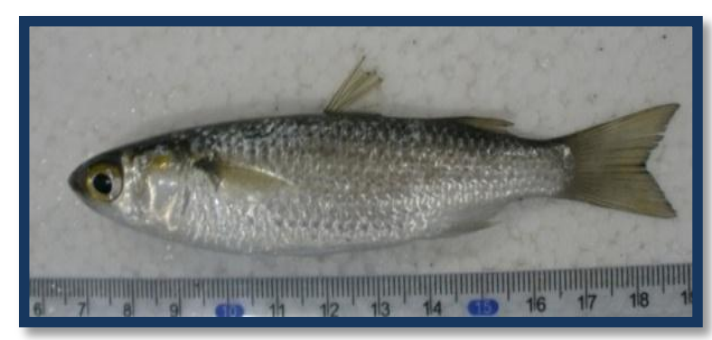

Gambar 1. Valamugil connesius

bawah mata. Dari 23 parameter yang dihitung maka ukuran morfometrik pada ikan Valamugil connesius pada tiga muara sungai yaitu muara Sungai Poigar, muara Sungai Maruasey dan muara Sungai Talawaan bervariasi. Seperti kisaran panjang garpu pada Valamugil connesius yang ditemukan di muara Sungai Poigar memiliki perbedaan dengan Valamugil connesius yang ditemukan di muara Sungai Maruasey. Tetapi sebaliknya terdapat persamaan pada kisaran panjang garpu antara Valamugil connesius di muara Sungai Likupang dan muara Sungai Poigar. Jadi perbandingan morfometrik bagianbagian tubuh Valamugil connesius pada tiga tempat yang berbeda bervariasi. Variasi morfometrik dari Valamugil connesius 
diakibatkan oleh perbedaan substrat antara tiga muara sungai (Brett, 1979).

\section{Meristik}

Hasil perhitungan meristik yaitu perumusan jari-jari sirip dan jumlah insang (Gill Racker) pada diperoleh jumlah sirip dorsal, sirip anal, sirip pectoral, sirip caudal, sirip ventral pada Valamugil connesius yaitu D IV.9, A III.9, P 16-17, C 18, VI.5 sedangkan jumlah insang (Gill Racker) yaitu 4-6+5-8. Jumlah meristik Valamugil connesius pada muara sungai yang berbeda tidak mengalami perbedaan. Meristik tidak dipengaruhi oleh faktor lingkungan seperti salinitas, $\mathrm{pH}$, oksigen dan suhu tetapi merupakan turunan dari indukinya genotip (Brett, 1979).

\section{Pola Warna}

Hasil identifikasi pola warna Valamugil connesius pada tiga muara sungai yang berbeda yaitu tubuh Valamugil connesius bewarna coklat kekuningkuningan bagian belakang bewarna gelap abu-abu. Warna perak terdapat pada sirip perut dan dada ikan berwarna bintik-bintik hitam. Pola pigmentasi yaitu longitudinal dan bewarna keperakan.

$\begin{array}{ll}\text { Deskripsi } & \text { Mugil cephalus } \\ \text { Kingdom } & \text { : Animalia } \\ \text { Phylum } & \text { : Chordata } \\ \text { Sub phylum } & \text { : Vertebrata } \\ \text { Super Class } & \text { : Osteichthyes } \\ \text { Class } & \text { : Actinopterygii } \\ \text { Ordo } & \text { : Perciformes } \\ \text { Famili } & \text { : Mugilidae } \\ \text { Genus } & \text { : Mugil } \\ \text { Spesies } & : \text { Mugil cephalus }\end{array}$

\section{Morfologi}

Berdasarkan hasil pengamatan bentuk tubuh dari Mugil cephalus yaitu simetris bilateral, fusiform, bentuk mulut dapat disembulkan, posisi mulut inferior, tidak memiliki sungut, posisi sirip ventral terhadap sirip pectoral torasik, gurat sisi lebih dari satu , bentuk sirip ekor bercagak, tipe sirip dorsal ganda dan bentuk sisik ctenoid serta tidak mempunyai ciri khusus pada tubuhnya.

\section{Morfometrik}

Hasil perhitungan morfometrik pada diperoleh indeks proporsi antara bagianbagian tubuh Mugil cephalus di dua tempat yang berbeda terhadap panjang total tubuh setelah dirata-ratakan nilai paling tinggi adalah panjang garpu sedangkan nilai ratarata yang paling rendah adalah lebar bukaan mulut. Dari 23 parameter yang dihitung maka ukuran morfometrik pada ikan Mugil cephalus di dua muara sungai yaitu muara Sungai Maruasey dan muara Sungai Talawaan relatif sama. Dimana kisaran tubuhnya tidak begitu jauh berbeda.

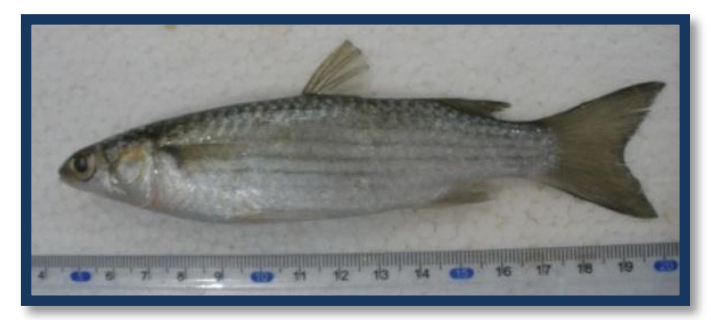

Gambar 2. Mugil cephalus

\section{Meristik}

Hasil perhitungan meristik yaitu perumusan jari-jari sirip dan jumlah insang (Gill Racker) pada diperoleh jumlah sirip dorsal, sirip anal, sirip pectoral, sirip caudal, sirip ventral pada Mugil cephalus yaitu D IV8-9, A III.8, P 16-19, C 19, V.5 sedangkan jumlah insang (Gill Racker) yaitu 4-7+5-7. Meristik Mugil cephalus pada muara sungai yang berbeda tidak mengalami perbedaan.

\section{Pola warna}

Pola warna Mugil cephalus pada dua muara sungai relatif sama yaitu bagian tubuh Mugil cephalus di dominasi warna keperakan sedangkan pada ekor warna coklat kehitaman. Sirip perut berwarna keperakan dan kuning-kuning sedangkan pada sirip dada bewarna putih kehitaman. Pola pigmentasi longitudinal dan bewarna kehitam-hitaman. 


\section{Deskripsi Liza macrolepis}

$\begin{array}{ll}\text { Kingdom } & \text { : Animalia } \\ \text { Phylum } & \text { : Chordata } \\ \text { Sub phylum } & \text { : Vertebrata } \\ \text { Super Class } & \text { : Osteichthyes } \\ \text { Class } & \text { : Actinopterygii } \\ \text { Ordo } & \text { : Perciformes } \\ \text { Famili } & \text { : Mugilidae } \\ \text { Genus } & \text { : Liza } \\ \text { Spesies } & \text { : Liza macrolepis }\end{array}$

\section{Morfologi}

Berdasarkan hasil pengamatan bentuk tubuh simestris bilateral, fusiform, bentuk mulut dapat disembulkan, bentuk ekor berlekuk ganda, posisi ventrl terhadap pectoral torasik, tidak memiliki sungut sedangkan sisik berbentuk ctenoid.

\section{Morfometrik}

Hasil perhitungan morfometrik pada Diperoleh indeks proporsi antara bagianbagian tubuh ikan Liza macrolepis terhadap panjang total tubuh setelah dirata-ratakan nilai paling tinggi adalah 0,951 yaitu panjang garpu berarti $95,1 \%$ dari panjang total. Nilai paling rendah adalah lebar bukaan mulut dengan lebar 0,015 berarti $1,5 \%$ terhadap panjang total. Spesies Liza macrolepis hanya ditemukan di Muara Sungai Maruasey.

\section{Meristik}

Hasil perhitungan meristik yaitu perumusan jari-jari sirip dan jumlah insang

\section{Deskripsi Liza parmata}

$\begin{array}{ll}\text { Kingdom } & \text { : Animalia } \\ \text { Phylum } & \text { : Chordata } \\ \text { Sub phylum } & \text { : Vertebrata } \\ \text { Super Class } & \text { : Osteichthyes } \\ \text { Class } & : \text { Actinopterygii } \\ \text { Ordo } & : \text { Perciformes } \\ \text { Famili } & : \text { Mugilidae } \\ \text { Genus } & : \text { Liza } \\ \text { Spesies } & \text { : Liza parmata }\end{array}$

\section{Morfologi}

Dari hasil pengamatan yang dilakukan, Liza parmata bentuk dasar tubuh ikan ini adalah fusiform, sedangkan dari samping antenuate, bentuk mulut dapat disembulkan, posisi mulut subterminal, memiliki sirip perut, bentuk sirip ekor

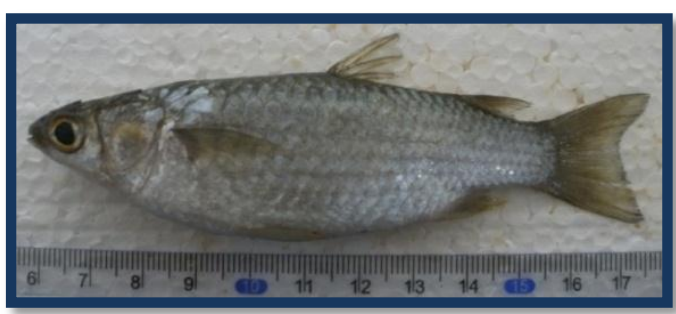

Gambar 3. Liza macrolepis

(Gill Racker) pada diperoleh jumlah sirip dorsal, sirip anal, sirip pectoral, sirip caudal, sirip ventral pada Liza macrolepis yaitu D IV8, A III.8, P 16, C 18, VI.5 sedangkan jumlah tapis insang (Gill Racker) yaitu 4$5+5-6$. Khususnya pada sirip dorsal, anal dan ventral memiliki sirip keras dan lunak sedangkan pada sirip yang lain hanya memiliki sirip yang lunak.

\section{Pola warna}

Pada bagian belakang Liza macrolepis bewarna kehijau-hijauan dan keperakan pada sirip perutnya. Terdapat bintik hitam pada bagian sirip dada. Pola pigmentasi yaitu longitudinal dengan harisgaris hitam.

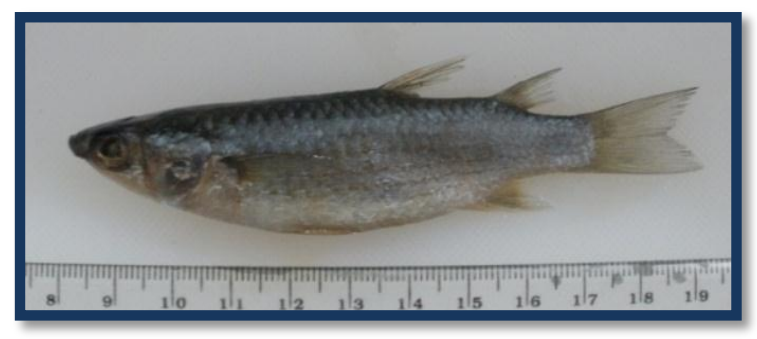

Gambar 4. Liza paramata

bercagak, tipe sirip dorsal terhadap sirip dada ialah torasik sedangkan bentuk sisik ctenoid.

\section{Morfometrik}

Hasil perhitungan morfometrik pada diperoleh indeks proporsi antara bagianbagian tubuh ikan Liza parmata terhadap panjang total tubuh setelah dirata-ratakan 
nilai paling tinggi adalah 0,934 yaitu panjang garpu berarti $93,4 \%$ dari panjang total. Nilai paling rendah adalah lebar bukaan mulut dengan lebar 0,013 berarti $1,3 \%$ terhadap panjang total. Spesies Liza parmata hanya ditemukan di muara Sungai Poigar.

\section{Meristik}

Hasil perhitungan meristik yaitu perumusan jari-jari sirip dan jumlah insang (Gill Racker) pada diperoleh jumlah sirip dorsal, sirip anal, sirip pectoral, sirip caudal, sirip ventral pada Liza parmata yaitu D IV8-

\section{Deskripsi Oedalechilus labiosus \\ Kingdom : Animalia \\ Phylum : Chordata \\ Sub phylum : Vertebrata \\ Super Class : Osteichthyes \\ Class : Actinopterygii \\ Ordo : Perciformes \\ Famili : Mugilidae \\ Genus : Oedalechilus \\ Spesies : Oedalechilus labiosus}

\section{Morfologi}

Berdasarkan hasil penelitian bentuk morfologi Oedalechilus labiosus adalah sebagai berikut bentuk tubuh simestris bilateral, bentuk mulut adapat disembulkan, bentuk ekor berlekuk ganda, posisi ventral terhadap pectoral torasik.

\section{Morfometrik}

Hasil perhitungan morfometrik pada diiperoleh indeks proporsi antara bagianbagian tubuh ikan Oedalechilus labiosus terhadap panjang total tubuh setelah dirataratakan nilai paling tinggi adalah 0,926 yaitu panjang garpu berarti $92,6 \%$ dari panjang total. Nilai paling rendah adalah lebar bukaan mulut dengan lebar 0,017 berarti 1,7\% terhadap panjang total. Spesies Oedalechilus
9, A III.7-9, P 16, C 18, VI.5 sedangkan jumlah insang (Gill Racker) yaitu 4-5+5-7. Khususnya pada sirip dorsal, anal dan ventral memiliki sirip keras dan lunak sedangkan pada sirip yang lain hanya memiliki sirip yang lunak.

\section{Pola warna}

Bagian tubuh Liza parmata umumnya sisik bewarna putih keperakan dan pada ujung sirip ekor ada warna hitam muda sedangkan pada bagian dorsal bewarna kehitam-hitaman.

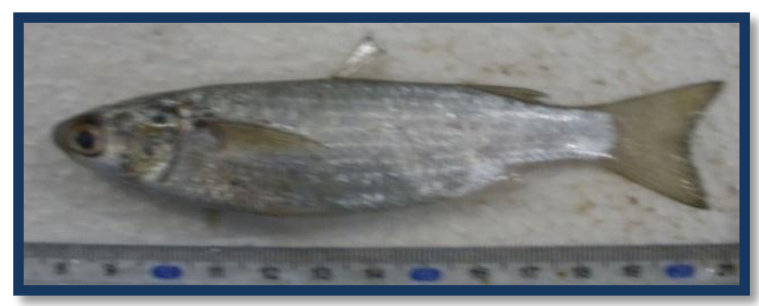

Gambar 5. Oedalechilus labiosus

labiosus hanya ditemukan di muara sungai Ranoyapo.

\section{Meristik}

Hasil perhitungan meristik yaitu perumusan jari-jari sirip dan jumlah insang (Gill Racker) pada diperoleh jumlah sirip dorsal, sirip anal, sirip pectoral, sirip caudal, sirip ventral pada Oedalechilus labiosus yaitu D IV 7-9, A III.9, P 16-18, C 18, VI.5 sedangkan jumlah insang (Gill Racker) yaitu 4-5+5-7.

\section{Pola Warna}

Tubuh abu-abu gelap sedangkan pada bagaian keperakan , sirip perut berwarna putih.kehitam-hitaman pada bagian dada. Bagian tubuh di dominasi warna putih kebiruan sedangkan pada sirip putih keperakan.

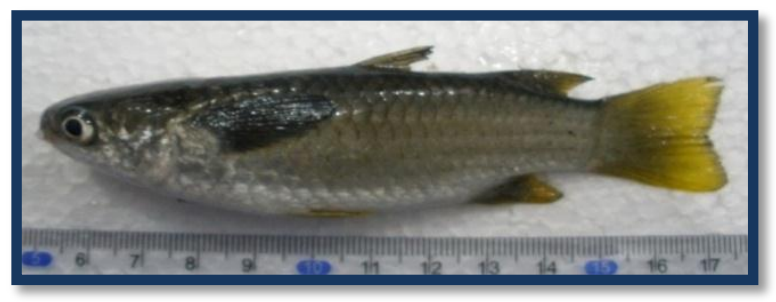

Gambar 6. Liza vaigensis

$\begin{array}{ll}\text { Deskripsi Liza } & \text { vaigensis } \\ \text { Kingdom } & \text { : Animalia } \\ \text { Phylum } & \text { : Chordata } \\ \text { Sub phylum } & \text { : Vertebrata } \\ \text { Super Class } & \text { : Osteichthyes } \\ \text { Class } & \text { : Actinopterygii } \\ \text { Ordo } & \text { : Perciformes } \\ \text { Famili } & \text { : Mugilidae } \\ \text { Genus } & \text { : Liza } \\ \text { Spesies } & : \text { Liza vaigensis }\end{array}$




\section{Morfologi}

Berdasarkan hasil pengamatan Liza vaigensis memiliki bentuk morfologi yaitu tubuh simestris bilateral dengan mulut dapat disembulkan, posisi mulut suterminal dengan bentuk sirip ekor berlekuk tunggal. Posisi sirip ventral terhadap sirip pectoral adalah torasik serta bentuk sisik adalah ctenoid dan tidak memiliki ciri khusus.

\section{Morfometrik}

Hasil perhitungan morfometrik pada diperoleh indeks proporsi antara bagianbagian tubuh Liza vaigensis di dua tempat yang berbeda terhadap panjang total tubuh setelah dirata-ratakan nilai paling tinggi adalah panjang garpu sedangkan nilai ratarata yang paling rendah adalah lebar bukaan mulut. Dari 23 parameter yang dihitung maka ukuran morfometrik pada ikan Liza vaigensis di dua muara sungai yaitu Muara Sungai Ranoyapo dan Muara Sungai Talawaan maka kisaran panjang tubuh relatif sama. Seperti pada panjang garpu Liza vaigensis yang ditemukan di Muara Sungai Ranoyapo kisaran tubuhnya tidak begitu jauh berbeda, begitupun pada bagian-bagian tubuh yang lain.

\section{Meristik}

Hasil perhitungan meristik yaitu perumusan jari-jari sirip dan jumlah insang (Gill Racker) pada diperoleh jumlah sirip dorsal, sirip anal, sirip pectoral, sirip caudal, sirip ventral pada Liza vaigensis yaitu D IV8-9, A III, P 16, C 19-20, VI.5 sedangkan jumlah insang (Gill Racker) yaitu 4-5+5-7. Meristik Liza vaigensis pada muara sungai yang berbeda tidak mengalami perbedaan.

\section{Pola Warna}

Bagian tubuh didominasi warna putih keperakan, tetapi pada sirip bewarna kuning kecuali pada sirip dada bewarna kehitam-hitaman. Sirip punggung merupakan percampuran kuning dan sidikit hitam.

\section{KESIMPULAN}

Jumlah sampel ikan Famili
Mugilidae yang ditemukan sebanyak 138
ekor dan hasil identifikasi ditemukan 6
spesies dari 3 genus yaitu Liza parmata, Liza
vaigensis, Liza macrolepis, Mugil cephalus,

Valamugil connesius, Oedalechilus labiosus. Valamugil connesius yang ditemukan di muara Sungai Likupang, muara Sungai Poigar dan muara Sungai Maruasey memiliki ukuran-ukuran morfometrik yang bervariasi. Sedangkan untuk Liza vaigensis yang ditemukan di muara Sungai Ranoyapo dan muara Sungai Talawaan serta Mugil cephalus yang ditemukan di muara Sungai Maruasey dan muara Sungai Talawaan memiliki ukuran morfometriknya relatif sama. Perbandingan meristik untuk spesies ikan yang sama pada muara sungai yang berbeda memiliki jumlah yang sama pada perumusan sirip dan Gill Racker.

\section{DAFTAR PUSTAKA}

Brett, C.E.,1979. Water Quality in Warm Water Fish Pond Cultere. Auburn University Alabama. USA.

Hutabarat, 2000. Pengantar Oseonografi. UI Press. Jakarta.

Kottelat, M. A. J. Whitten. S. N. Kartikasari dan S. Wirjoatmojo. 1993. Freshwater of Western Indonesia and Sulawesi. Periplus Edition. London.

Nelson, J.S., 1984. Fisher of The Word. John Wiley and Sons. New York.

Odum. $1996 . \quad$ Dasar-Dasar Ekologi.
Universitas Gadjah Mada Perss.
Yogyakarta. 